\title{
Quantification of Diclofenac at Trace Levels in Pharmaceutical and Urine Samples Using Kinetic Spectrophotometric Method
}

\author{
FATEMEH FALLAH, MASOUD REZA SHISHEHBORE* and ALI SHEIBANI
}

Department of Chemistry, Yazd Branch, Islamic Azad University, Yazd, Iran.

${ }^{*}$ Corresponding author E-mail: shishehbor47 @ iauyazd.ac.ir

http://dx.doi.org/10.13005/ojc/320181

(Received: December 12, 2015; Accepted: February 03, 2016)

\begin{abstract}
Diclofenac, a non-steroidal anti-inflammatory drug, is prescribed to reduce inflammation and as an analgesic reducing pain in certain conditions. In this study, a sensitive reaction system for quantitative determination of diclofenac was introduced. The method is based on the catalytic effect of diclofenac on the Orange G-bromate reaction system. The change in absorbance was followed spectrophotometrically as a criterion of the oxidation reaction progress at $478.5 \mathrm{~nm}$. The effective reaction variables were optimized. Under optimized experimental conditions, calibration curve was linear over the range $0.035-2.7 \mathrm{mg} / \mathrm{l}$ and the detection limit $\left(3 \mathrm{~s}_{\mathrm{b}} / \mathrm{m}\right)$ was $0.014 \mathrm{mg} / \mathrm{l}$ for five replicate determinations of blank signal. The interfering effect of various species was also investigated. The developed procedure was applied for the determination of diclofenac in pharmaceutical and biological samples satisfactorily.
\end{abstract}

Key words: Diclofenac, Orange G, Pharmaceutical and Urine Samples, Kinetic Spectrophotometry.

\section{INTRODUCTION}

Diclofenac, ((2-(2,6-dichloranilino) phenylacetic acid) is a nonsteroidal antiinflammatory drug that was introduced in UK in 1979. It is used to treat pain, inflammatory disorders and dysmenorrhea. It works by reducing hormones that cause inflammation and pain in the body. Longterm use of diclofenac predisposes for peptic ulcer. It is available as tablet, oral injection solution and suppository. It is also available over-the-counter in some countries. Therefore, diclofenac is a widely used drug that so easily available ${ }^{1,2}$. Regarding to widespread of the use of diclofenac, developing a rapid, reliable, and low cost procedure for quantitative determination of it in real samples with different matrices is necessary.

Various reports have been found for quantitation of diclofenac in real samples with 
different matrices. The most common methods are including liquid chromatography ${ }^{3-5}$, electrochemical techniques ${ }^{6,7}$ and spectrophotometry ${ }^{8,9}$. Along with the high sensitivity and precision of chromatographic methods, hard operation and set up cost are the main disadvantages of them. Also, low repeatability and poor selectivity are the main drawback of the electrochemical methods.

Catalytic spectrophotometric method as a low cost and simple method with sufficient accuracy is considered as an alternative for the determination of trace elements in samples with different matrices such as foods ${ }^{10}$, biological and pharmaceutical ${ }^{11,12}$ samples.

In this report, for the first time, a sensitive and rapid kinetic spectrophotometric method for quantitation of diclofenac was reported. The method is based on the catalytic effect of diclofenac on the Orange G-bromate reaction system. The developed procedure was applied for the determination of diclofenac in real samples with satisfactory results.

\section{MATERIALS AND METHODS}

Doubly distilled water and analytical reagent grade chemicals were used. Diclofenac as diclofenac sodium (Sigma) stock solution 75.0 $\mathrm{mg} / \mathrm{l}$ was prepared just before use by dissolving appropriate amount of diclofenac sodium in water and diluted to the mark in a $100 \mathrm{~mL}$ calibrated flask. Working solution was prepared by serial dilution. A solution of Orange $\mathrm{G}\left(6.6 \times 10^{-4} \mathrm{~mol} / \mathrm{l}\right)$ was prepared by dissolving $0.2985 \mathrm{~g}$ of Orange $\mathrm{G}$ (Merck) in water and diluting to $1.0 \mathrm{~L}$ with water. Sulfuric acid solution (3.0 mol/l) was prepared by appropriate dilution of<smiles>O=S(=O)(O)c1cc(O)c2c(/N=N/c3ccccc3)c(S(=O)(=O)O)cc(O)c2c1</smiles>

Scheme 1: Molecular structure of Orange G conc. sulfuric acid (Merck). A $0.1 \mathrm{~mol} / \mathrm{l}$ of potassium bromate solution was prepared by dissolving 16.7100 $\mathrm{g}$ of $\mathrm{KBrO}_{3}$ (Merck) in water and diluting to $1.0 \mathrm{I}$ in a calibrated flask.

\section{Apparatus}

A double beam Shimadzu UV-Vis spectrophotometer (160A, Japan) with 1-cm matched glass cells was used to measure the absorbance. A thermostated water bath (Heidolph, Germany) was used to keep the temperature of all solutions at the working temperature $\left(25.0 \pm 0.1^{\circ} \mathrm{C}\right)$. A stop-watch was used to record the reaction time.

\section{Recommended procedure}

The catalyzed reaction was studied spectrophotometrically by monitoring the change in absorbance of the reaction mixture at 478.5 $\mathrm{nm}\left(\lambda_{\text {max }}\right)$. For this purpose, to a series of $10 \mathrm{ml}$ volumetric flasks, $1.0 \mathrm{ml}$ of $6.6 \times 10^{-4} \mathrm{~mol} / \mathrm{l}$ of Orange G solution, $1.5 \mathrm{ml}$ of $3.0 \mathrm{~mol} / \mathrm{l}$ sulfuric acid solution and the standard solutions containing 0.35 - 27.0 $\mu \mathrm{g}$ of diclofenac were added. The solution was thoroughly mixed and diluted to $8 \mathrm{ml}$ with water. Then, $0.4 \mathrm{ml}$ of $0.1 \mathrm{~mol} / \mathrm{l}$ of bromate solution was added and diluted to the mark. A time measurement was started just after adding the last drop of the oxidant. A portion of the mixed solution was transferred to a glass cell. The absorbance of catalysed reaction $\left(\Delta A_{\mathrm{s}}\right)$ was measured against water at $\lambda_{\max }$ and $30^{\circ} \mathrm{C}$ and $120 \mathrm{~s}$ by time interval $30 \mathrm{~s}$. The measurement in the absence of diclofenac was repeated to obtain the values for the uncatalysed reaction $\left(\Delta A_{b}\right)$. The difference in the absorbance change was considered as the response $\left(\Delta A=\Delta A_{\mathrm{s}}-\Delta A_{\mathrm{b}}\right)$.

The calibration curve was constructed by plotting the response against the diclofenac concentration.

\section{Procedure of sample preparation}

Ten diclofenac tablets (in each dosage) were weighed, powdered and mixed thoroughly. An amount corresponding to the weight of a tablet was weighed, and dissolved with water. After 10 min sonication, the sample was filtered through a Whatman filter paper (No. 1), transferred to a $25 \mathrm{ml}$ volumetric flask and diluted to the mark with water. The diclofenac injection solution was transferred to a $100 \mathrm{ml}$ volumetric flask. $0.2 \mathrm{~g}$ of $1 \%$ topical gel was 
weighed accurately and $2 \mathrm{ml}$ of acetone was added. The solution was sonicated at $30 \stackrel{\circ}{ } \mathrm{C}$ for ten minutes. After filtration through Whatman filter paper (No. 1), the solution was transferred to a $25 \mathrm{ml}$ volumetric flask and diluted to the mark with water ${ }^{13}$.

Diclofenac was also determined in human urine as biological sample. The sample was collected from persons who had not taken the drug. The collected sample was purified using liquid-liquid extraction as follow: $5 \mathrm{ml}$ of the sample was mixed with $5 \mathrm{ml}$ of chloroform and shacked well. After centrifugation at $4000 \mathrm{rpm}$, the purified sample was transferred to $25 \mathrm{ml}$ volumetric flask and analysed according to the developed procedure ${ }^{14}$.

\section{RESULTS AND DISCUSSIONS}

Orange G, (Acid Orange 10, see Scheme 1 for molecular structure) is a synthetic azo dye that can be used in histology for staining formulation. In addition, it is used as $\mathrm{pH}$ indicator and color marker in electrophoresis. The product of Orange G oxidation is a colorless compound ${ }^{15}$. Also, it was used as a reagent for the determination of dexamethasone ${ }^{12}$ and ascorbic acid ${ }^{15}$.

Evaluating the capability of the selected reaction system (Orange $\mathrm{G}$, sulfuric acid and bromate) for quantitative determination of diclofenac was investigated by following the change in absorbance in absence and presence of it. Comparison of the results indicated that trace amounts of diclofenac could be increase the reaction rate seriously. Therefore, the proposed reaction system can be used for the determination of diclofenac at trace levels.

The suggested reaction mechanism of the proposed reaction system may be represented as follow:

The uncatalysed reactions that resulted to blank signal $\left(\Delta A_{b}\right)$ carry out in a cyclic way.

Orange $\mathrm{G}$ as a dye indicator in reduced form can be oxidized by bromate in acidic media to produce a colorless product (Orange $\mathrm{G}$ in oxidized form) and bromide (Reaction 1). The reaction is slow. Bromine was generated in presence of bromide in acidic media based on a well-known reaction (Reaction 2).

Oxidation of Orange $\mathrm{G}$ by bromine was down faster than oxidation by bromate (Reaction 3 ).

$$
\begin{aligned}
& \text { Orange } \mathrm{G}_{(\mathrm{Red})}+\mathrm{BrO}_{3}^{-}+6 \mathrm{H}^{+} \rightarrow \text { Orange } \mathrm{G}_{(\mathrm{Ox})}+\mathrm{Br} \\
& +3 \mathrm{H}_{2} \mathrm{O} \\
& 6 \mathrm{BrO}_{3}^{-}+10 \mathrm{H}^{+}+12 \mathrm{Br}^{-} \rightarrow 6 \mathrm{Br}_{2}+6 \mathrm{H}_{2} \mathrm{O}
\end{aligned}
$$

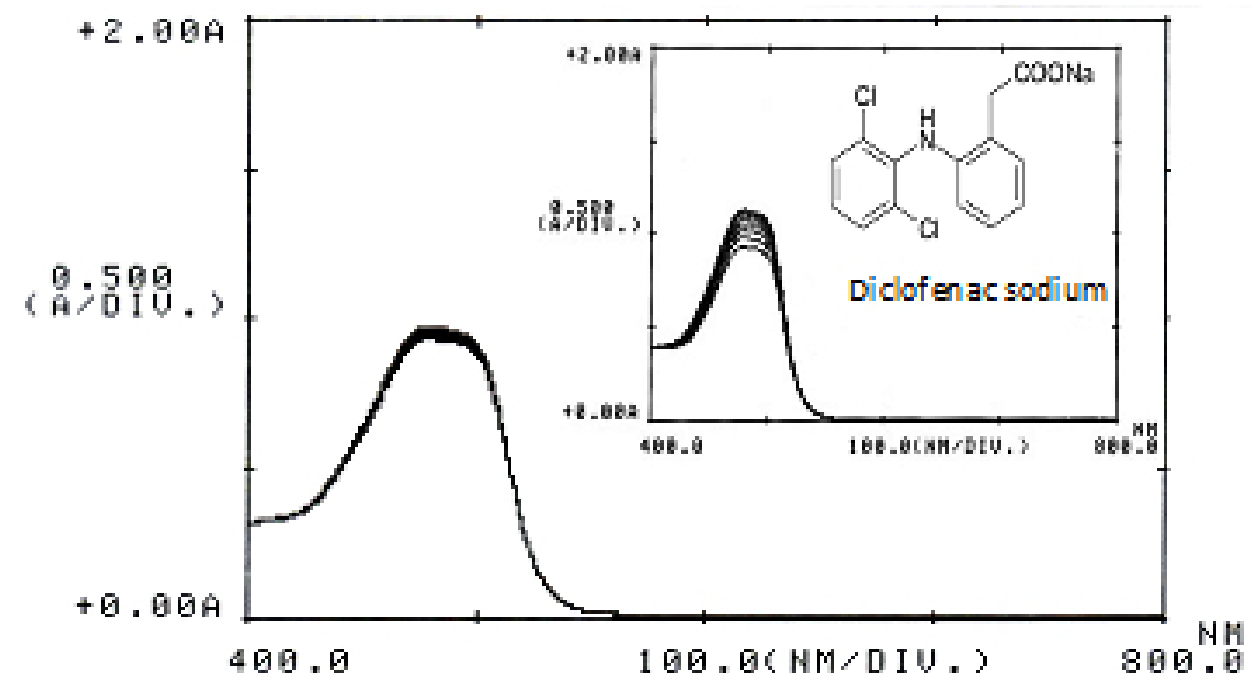

Fig. 1: Absorption spectra of the uncatalysed reaction. (Conditions: Orange G, $59.4 \mu \mathrm{mol} / \mathrm{l}$; sulfuric acid, $0.39 \mathrm{~mol} / \mathrm{l}$; bromate, $4.0 \mathrm{mmol} / \mathrm{l} ; 25^{\circ} \mathrm{C}$ and $360 \mathrm{~s}$ ). Inset shows the absorption spectra of the catalysed reaction (in persence of $0.75 \mathrm{mg} / \mathrm{l}$ of diclofenac) and molecular structure of diclofenac sodium 
Orange $\mathrm{G}_{(\mathrm{Red})}+\mathrm{Br}_{2}+\mathrm{H}^{+} \rightarrow$ Orange $\mathrm{G}_{(\mathrm{Ox})}+2 \mathrm{Br} \ldots$

Also, diclofenac in reduced form can be oxidized by bromine (Reaction 4).

Diclofenac $_{(\mathrm{Red})}+\mathrm{Br}_{2}+\mathrm{H}^{+} \rightarrow 2 \mathrm{Br}+$ Diclofenac $_{(\text {ox }}$

Based on the proposed mechanism, $\mathrm{Br}^{-}$ generation was increased by oxidation of diclofenac in persence of $\mathrm{Br}_{2}$ that resulted to increasing the possibility of decolorization of Orange G. Therefore, the change in absorbance in persence of diclofenac was increased dramatically and diclofenac was shown the catalytic effect (Fig.1).

In orther to obtain the maximum sensitivity as employing the proposed procedure, the effective variables must be optimized. The maximum response was considered to obtain the most sensitive results.

The effect of Orange $G$ concentration on the rate of reaction was studied over the range $46.2-$ $72.6 \mu \mathrm{mol} / \mathrm{l}$. As it an be seen in Fig. 2, the sensitivity was increased up to $62.7 \mu \mathrm{mol} / \mathrm{l}$ of Orange G. Dye aggregation maybe resulted to decrease the reaction rate at higher concentrations. Thus, $62.7 \mu \mathrm{mol} / \mathrm{l}$ of
Orange $\mathrm{G}$ as optimum concentration was selected for further study.

The effect of sulfuric acid concentration on the catalyzed and uncatalyzed reactions was studied over the range of 0.42 to $0.51 \mathrm{mmol} / \mathrm{l}$ (Fig. 3). The maximum sensitivity was obtained at $0.46 \mathrm{mmol} / \mathrm{l}$, whereas at higher concentrations the sensitivity was decreased. It may be attributed to protonation of Orange $\mathrm{G}$ at higher acid concentrations that makes its oxidaion to be quite difficult. Therefore, $0.46 \mathrm{~mol} / \mathrm{l}$ of sulfuric acid was used for further study.

The effcet of bromate concentration on the reaction rate was studied in concentration range 3.0 $-5.0 \mathrm{mmol} / \mathrm{l}$. As shown in Fig. 4 , the net reaction rate was increased up to $4.0 \mathrm{mmol} / \mathrm{l}$ which was selected as being the optimum concentration of oxidant.

The effect of the temperature on the reaction rate was studied under optimum experimental conditions in temperature range of 20 to $40^{\circ} \mathrm{C}$. Increasing the temperature up to $30{ }^{\circ} \mathrm{C}$ caused an increase in the sensitivity, whereas at higher temperatures it decreased. Thus, $30^{\circ} \mathrm{C}$ was selected as being the optimum temperature.

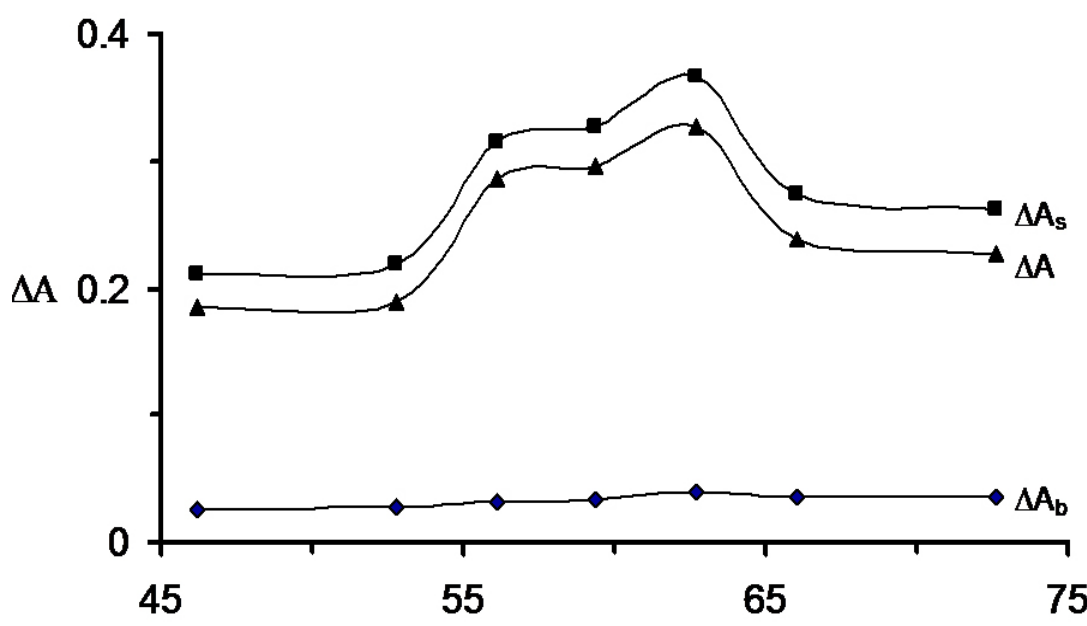

[Orange G] / $\mu \mathrm{mol} /$

Fig. 2: Effect of Orange $\mathrm{G}$ concentration on the rate of uncatalysed ( $\triangle \mathrm{Ab}$ ) and catalysed ( $\triangle \mathrm{As})$ reactions and response $(\Delta A)$. (Conditions: sulfuric acid, $0.45 \mathrm{~mol} / \mathrm{l}$; diclofenac, $0.75 \mathrm{mg} / \mathrm{l}$; bromate, $4.0 \mathrm{mmol} / \mathrm{l} ; 25^{\circ} \mathrm{C}$ and $270 \mathrm{~s}$ ). 
The optimum time was found by measuring the change in the absorbance during $30-270 \mathrm{~s}$. The reaction rate increased up to $120 \mathrm{~s}$, and in longer times the reaction rate was almost constant. Therefore, $120 \mathrm{~s}$ was selected for further study.

Calibration curve and detection limit

Calibration curve that was constructed by plotting the response against diclofenac concentration was linear over the range $0.035-2.7$ $\mathrm{mg} / \mathrm{l}$ of diclofenac. The regression equation of the calibration curve gave as equations 5 .

$$
\Delta \mathrm{A}=0.411 \text { [diclofenac] } 0.0043\left(\mathrm{R}^{2}=0.9997\right)
$$

where $\Delta A$ is the difference in the absorbance between the blank and the sample signals,

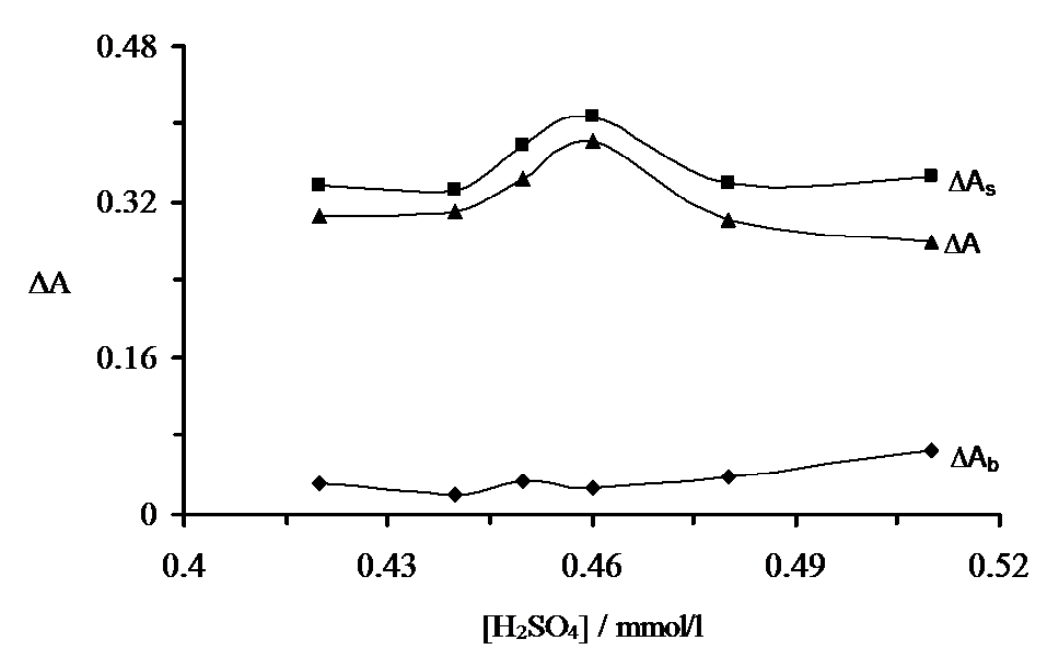

Fig. 3: Effect of sulfuric acid concentration on the rate of uncatalysed $(\triangle \mathrm{Ab})$ and catalysed $(\triangle \mathrm{As})$ reactions and response $(\Delta \mathrm{A})$. (Conditions: Orange G, $62.7 \mu \mathrm{mol} / \mathrm{l}$; diclofenac, $0.75 \mathrm{mg} / \mathrm{l}$; bromate, $4.0 \mathrm{mmol} / \mathrm{l} ; 25^{\circ} \mathrm{C}$ and $\left.270 \mathrm{~s}\right)$.

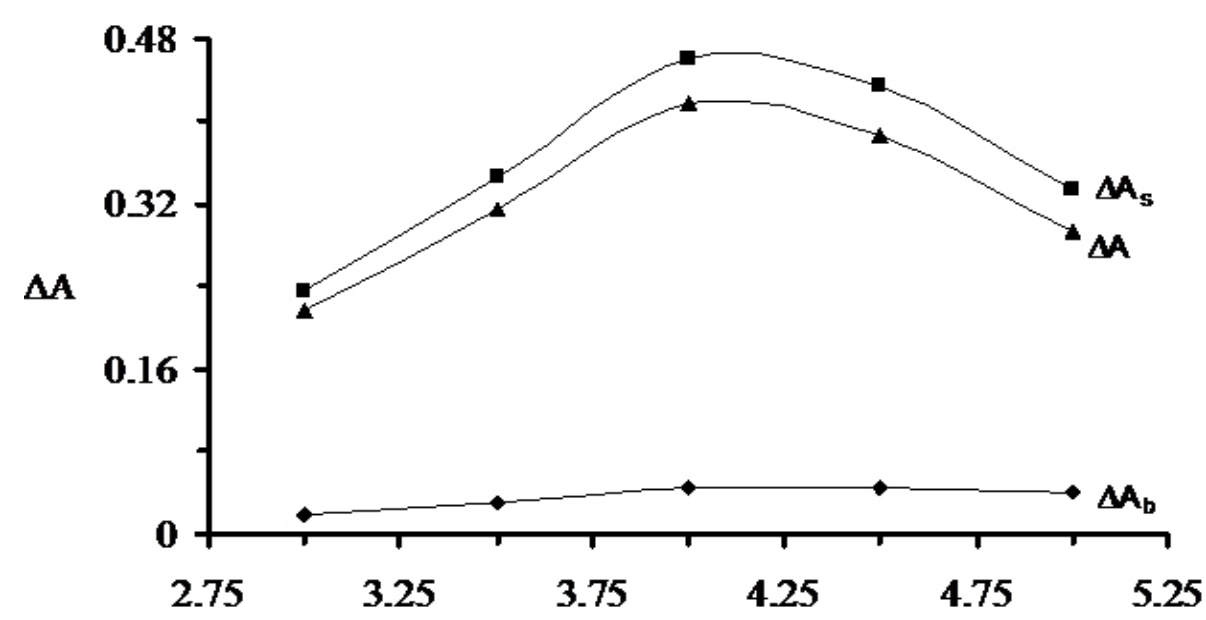

\section{$\left[\mathrm{BrO}_{3}\right] / \mathrm{mmo}$}

Fig. 4: Effect of bromate concentration on the rate of uncatalysed $\left(\Delta \mathbf{A}_{b}\right)$, catalysed $\left(\Delta \mathbf{A}_{s}\right)$ reactions and response $(\triangle \mathrm{A})$. (Conditions: Orange $\mathrm{G}, 62.7 \mu \mathrm{mol} / \mathrm{l}$; sulfuric acid, $0.46 \mathrm{mmol} / \mathrm{l}$; diclofenac, 0.75 $\mathrm{mg} / \mathrm{l} ; 25^{\circ} \mathrm{C}$ and $\left.270 \mathrm{~s}\right)$. 
[diclofenac] is the diclofenac concentration in $\mathrm{mg} / \mathrm{l}$ and $R^{2}$ is the correlation coefficient.

The limit of detection $\left(3 s_{\mathrm{b}} / m ; s_{\mathrm{b}}\right.$ is the standard deviation of the blank signal and $m$ is the slope of calibration curve) was $0.014 \mathrm{mg} / \mathrm{l}$ of diclofenac for five replicate determinations. The relative standard deviations $(n=5)$ were $1.84,1.59$ and $1.07 \%$ for $0.5,1.0$ and $2.0 \mathrm{mg} / \mathrm{l}$ of diclofenac, respectively.

\section{Interference study}

The interfering effect of foreign species on the determination of $1.0 \mathrm{mg} / \mathrm{l}$ of diclofenac was investigated. The tolerance limit was defined as the concentration of the added species causing an error more than $\pm 5 \%$ on analytical signal. The obtained results, given in Table 1, indicated that chloride and nitrite have seriously interfering effect, whereas not exist in real sample matrix.

\section{Application}

To evaluation the analytical applicability of the developed method, quantitative determination of diclofenac in various real samples with different matrices was done. Pharmaceutical sample preparation was performed as discussed previously. An appropriate amount of the samples were analyzed by the recommended procedure. The results of three replicate determinations were given in Table 2. The precision (RSD\%) is near to $1 \%$ for all of the analyzed pharmaceutical samples. The obtained values confirm the repeatability of the developed method. The reliability of the method was evaluated by statistical $t$ test. The experimental $t$ values for diclofenac tablet $(0.76,0.65$ and 2.03$)$, diclofenac injection solution (0.33 and 0.39$)$ and diclofenac topical gel (3.46) are differ from the critical value (4.30, 95\% confidence level and two degrees of freedom). Regarding to the difference between the experimental and critical $t$ values, the systematic error for the determination of diclofenac in pharmaceutical samples using the developed method is negligible. Also, the procedure was used for the determination of diclofenac in urine sample. After sample preparation, they were spiked with different amounts $(0.5,1.0$ and $1.5 \mathrm{mg} / \mathrm{l})$ of diclofenac and analysed using developed procedure. The obtained results were given in Table 3. The accuracy of the procedure was confirmed by recovery. The recovery values of the spiked urine sample, 99.0-104.0\%, confirm the slight systematic error during the quantitative determination of diclofenac. Successive applications of developed method for drug determination in pharmaceutical preparations and urine samples confirmed that the developed method is free from interfering effect of matrix effect and suitable for analysis of diclofenac in different real samples.

\section{CONCLUSIONS}

In this study, a sensitive kinetic spectrophotometric method for the detrmination of diclofenac at trace levels was reported. The developed procedure has advantages over the existing methods in cost, simplicity, ease of operation and applicability of the procedure for analysis of pharmaceutical and biological samples .

\section{ACKNOWLEDGMENT}

The athours are thakful to the Islamic Azad University-Yazd Branch for financial assistance of the research.

\section{REFERENCES}

1. Salmann, A. R.; Am. J. Med. 1986, 80, 29-33.

2. Breen, E. G.; McNicholl, J.; Cosgrove, E.; McCabe, J.; Stevens, F. M.; Gut. 1986, 27, 1390-1393.

3. Osorio, V.; Imbert-Bouchard, M.; Zonja, B.; Abad, J-L.; Pérez, S.; Barcelo, D.; J. Chromatogr. A 2014, 1347, 63-71.

4. Kaale, E.; Nyamweru B. C.; Manyanga, V.;
Chambuso, M.; Layloff, T.; Int. J. Chem. Anal. Sci. 2013, 4, 73-79.

5. Song, X-Y.; Shi, Y-P.; Chen, J.; Talanta 2012, 100, 153-161.

6. Oliveira, M, C., Bindewald, E. H.; Marcolino, L. H., Bergamini, M. F.; J. Electroanal. Chem. 2014, 732, 11-16.

7. Mokhtari. A.; Karimi-Maleh, H.; Ensafi. A. A.; Beitollahi, H.; Sens. Actuators B. 2012; 169, 
96-105.

8. Amiri-Pebdani, A.; Haji Shabani, A. M.; Dadfarnia, S.; Khodadoust, S.; Spectrochim. Acta A 2015; 147, 26-30.

9. Sena, M. M.; Chaudhry, Z. F.; Collins, C. H.; Poppi, R. J.; J. Pharm. Biomed. Anal. 2004, 36, 743-49.

10. Shishehbore, M. R.; Jokar, R.; Anal. Methods 2011; 3, 2815-21.

11. Shishehbore, M. R.; Asgharpoor, A.;
Nasirizadeh, N.; J. Chem. 2013, 4, 1-6.

12. Akhoundi-Khalafi, A. M.; Shishehbore, M. R.; Int. J. Anal. Chem. 2015, 5, 1-6.

13. Adhikari, L.; Jana, K.; Behera, A.; Moitra, S. K.; J. Pharm. Pharm. Sci. 2010, 3, 136-139.

14. Perez-Ruiz, T.; Martinez-Lozano, C.; Sanz, A.; Miguel, M. T. S.; J. Pharm. Biomed. Anal. 1997, 16, 249-254.

15. Shishehbore M. R.; Aghamiri, Z.; Iran. J. Pharm. Res. 2014; 12, 373-82, 